\title{
Failure Patterns of Reinforced Lightweight Aggregate Concrete (RLAC) Walls after High Temperature Jen-Hao Chi ${ }^{1, a}$, Yu-Chang Hsu', ${ }^{2, b}$, How-Ji Chen ${ }^{3, c}$ \\ ${ }^{1}$ Department of Fire Science, Wu Feng University, 117 Jianguo Rd., Sec.2, Minsyong, Chiayi, 62153 Taiwan \\ ${ }^{2}$ Department of Civil Engineering, National Chung Hsing University, 250 Kuo Kuang Road, Taichung, 40227 Taiwan \\ achi.jen-hao@wfu.edu.tw, bq110026@yahoo.com.tw, chojichen@nchu.edu.tw
}

Keywords: Reinforced lightweight aggregate concrete(RLAC) walls; Fire-resistance test; Failure patterns; Reinforced normalweight aggregate concrete wall (RNAC)

Abstract.This study utilizes and sinters the reservoir sediment to produce high-quality lightweight aggregates. Not only does the recycling of reservoir sediment into useful building material save resources, but it also increases the reservoir capacity, prolongs reservoir life, and is more conducive to environmental protection. This research focuses on this kind of reinforced lightweight aggregate concrete (RLAC) walls. After performing a standard temperature rising fire-resistance test, the failure patterns behavior of the wall sample are studied under a lateral horizontal load. The research results showed that the reinforced lightweight aggregate concrete wall retained its mechanics after the fire-resistance test. The test results also showed that RLAC and reinforced normalweight aggregate concrete (RNAC) walls exerted the same influence on failure patterns.

\section{Introduction}

For a long time, damages to structures caused by earthquake have been the focus of public attentions. Most research in the past also focused on the fields of seismic analysis, seismic design and seismic isolation. However, few studies were done on the materials used for the structure. As the weight of structure constructed with LWAC is lighter, the seismic force it generates is also smaller while withstanding the effects of earthquake acceleration [1-2]. In addition, better damping property of LWAC may reduce the dynamic response of the structure. Undoubtedly, under the same condition, the seismic capacity of LWAC is much better than that of NWAC. In contrast to most past research, which concentrate on the seismic capacity of NWAC, fewer research were conducted on RLAC walls, especially in the field of mechanics behavior of walls under repeated horizontal loads. Therefore, this paper explores the mechanics behavior of RLAC walls under the lateral effect of repeated horizontal loads after the fire-resistance test under standard temperature condition, as well as the results of the failure patterns of the wall specimens to evaluate the seismic resistance of RLAC after being treated with high temperature [3]. 


\section{Experimental Plan}

\section{Specimens planning}

To compare the differences on fire-resistance performances between RLAC and RNAC walls, this concrete specimens for this research include lightweight and normalweight aggregates with and without high temperatures with the consideration of vertical steel spacing at $10 \mathrm{~cm}, 20 \mathrm{~cm}$, and $30 \mathrm{~cm}$ and with the dimension (width $\times$ height $\times$ thickness) at $150 \mathrm{~cm} \times 150 \mathrm{~cm} \times 7.5 \mathrm{~cm}$ and $85 \mathrm{~cm} \times$ $150 \mathrm{~cm} \times 7.5 \mathrm{~cm}$, respectively. With regard to the specimens' number, size, and material properties, and the information on the 28-day compressive strength test for concrete walls, please refer to Table 1.

Table 1. Numbers and parameter of internal composition of the specimens.

\begin{tabular}{|c|c|c|c|c|c|c|}
\hline \multirow[b]{2}{*}{ Series* } & \multirow{2}{*}{$\begin{array}{l}\text { Wall size }(\mathrm{cm}) \\
(\mathrm{W} \times \mathrm{H} \times \mathrm{tw})\end{array}$} & \multirow{2}{*}{$\begin{array}{c}\text { Coarse } \\
\text { aggregate type }\end{array}$} & \multicolumn{2}{|c|}{ Vertical steel } & \multirow[b]{2}{*}{$\mathrm{W} / \mathrm{C}$} & \multirow{2}{*}{$\begin{array}{c}\mathrm{fc}^{\prime} \\
\left(\mathrm{kg} / \mathrm{cm}^{2}\right)\end{array}$} \\
\hline & & & $\begin{array}{l}\text { Number- } \\
\text { Steel spacing }\end{array}$ & $\rho$ & & \\
\hline LW85S10B & $85 \times 150 \times 7.5$ & $\begin{array}{l}\text { Lightweight } \\
\text { aggregate }\end{array}$ & \# 3-10cm & 0.00894 & 0.46 & 216.5 \\
\hline LW85S20B & $85 \times 150 \times 7.5$ & $\begin{array}{l}\text { Lightweight } \\
\text { aggregate }\end{array}$ & \# 3-20cm & 0.00447 & 0.46 & 201.3 \\
\hline LW85S30B & $85 \times 150 \times 7.5$ & $\begin{array}{l}\text { Lightweight } \\
\text { aggregate }\end{array}$ & $\# 3-30 \mathrm{~cm}$ & 0.00335 & 0.46 & 234.6 \\
\hline LW85S30 & $85 \times 150 \times 7.5$ & $\begin{array}{l}\text { Lightweight } \\
\text { aggregate }\end{array}$ & $\# 3-30 \mathrm{~cm}$ & 0.00335 & 0.46 & 196.3 \\
\hline LW150S30B & $150 \times 150 \times 7.5$ & $\begin{array}{l}\text { Lightweight } \\
\text { aggregate }\end{array}$ & $\# 3-30 \mathrm{~cm}$ & 0.00317 & 0.46 & 216.8 \\
\hline NW85S30B & $85 \times 150 \times 7.5$ & $\begin{array}{l}\text { Normalweight } \\
\text { aggregate }\end{array}$ & \# 3-30cm & 0.00335 & 0.66 & 196.9 \\
\hline NW85S30 & $85 \times 150 \times 7.5$ & $\begin{array}{l}\text { Normalweight } \\
\text { aggregate }\end{array}$ & $\# 3-30 \mathrm{~cm}$ & 0.00335 & 0.66 & 202.3 \\
\hline NW150S30B & $150 \times 150 \times 7.5$ & $\begin{array}{l}\text { Normalweight } \\
\text { aggregate }\end{array}$ & \# 3-30cm & 0.00317 & 0.66 & 211.6 \\
\hline
\end{tabular}

\section{Fire-resistance test}

The aforementioned wall specimens were placed in a high-temperature furnace for this study. The specimens were heated according to the standard temperature rising curve of ASTM E119. According to ASTM E119, the temperature in the furnace needs to reach $700^{\circ} \mathrm{C}$ within 10 minutes, and the heating shall continue for another 50 minutes until the final temperature reaches $950{ }^{\circ} \mathrm{C}[3]$. In addition, two thermocouples of $\mathrm{CH} 1$ and $\mathrm{CH} 3$ were buried inside specimens and a temperature test rod was mounted on the surface of the wall specimens at the location (see Figure 1) in order to obtain the interior and exterior temperature changes of the specimens. Finally, the wall specimens were removed after completing the aforementioned fire-resistance test for observation. After observing the surface damages caused by high temperature, the repeated horizontal thrust test was conducted.

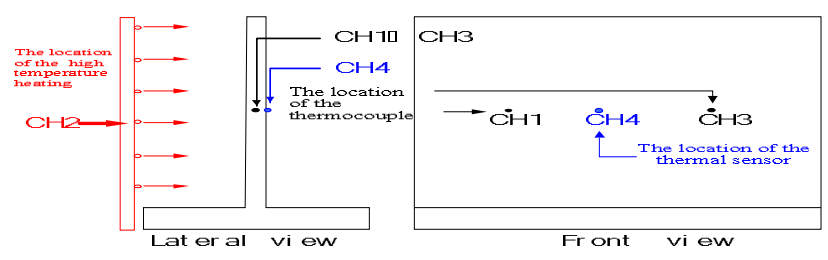

Figure 1. The location of measuring point for specimens in the fire-resistance test. 


\section{Horizontal thrust test and repeated horizontal thrust test}

In this study, the wall specimens were locked tightly with bolts on solid floor 28 days after casting and a horizontal thrust was exerted directly on them. The pressure head of the horizontal thrust equipment, a MTS device of 50 tons in weight, was mounted on the reaction wall. The readings from the signals were transformed into actual physical quantity by load cell for a series of analyses on the test results. As stated above, this study will apply repeated load force directly onto the wall specimens according to the test method. By means of displacement control, signal readings from the data collection system were transformed into actual physical quantity and then saved on a desktop as the files for test result analysis.

\section{Analysis and discussion on the test results}

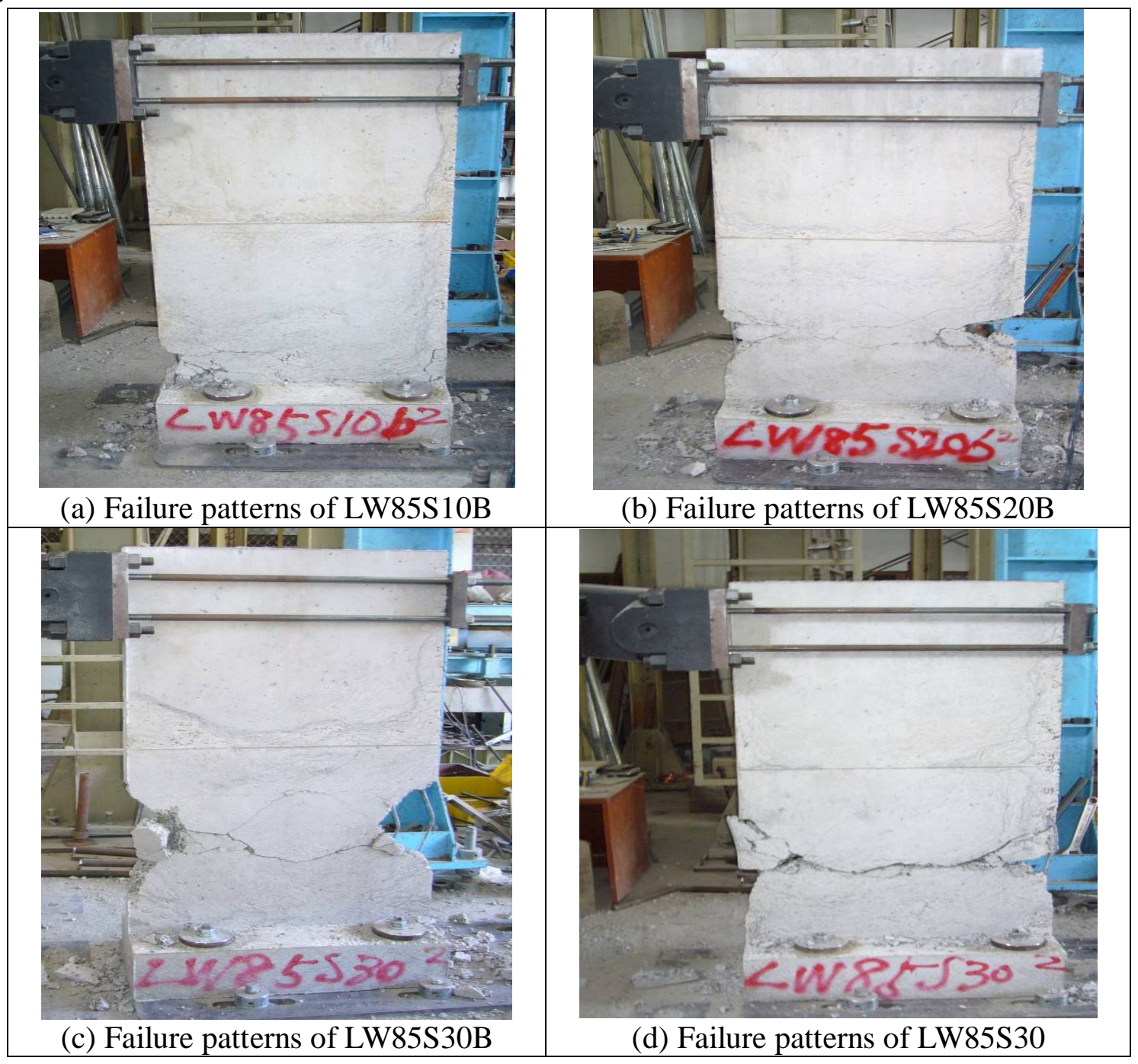

Figure 2. Failure patterns of RLAC wall specimens 


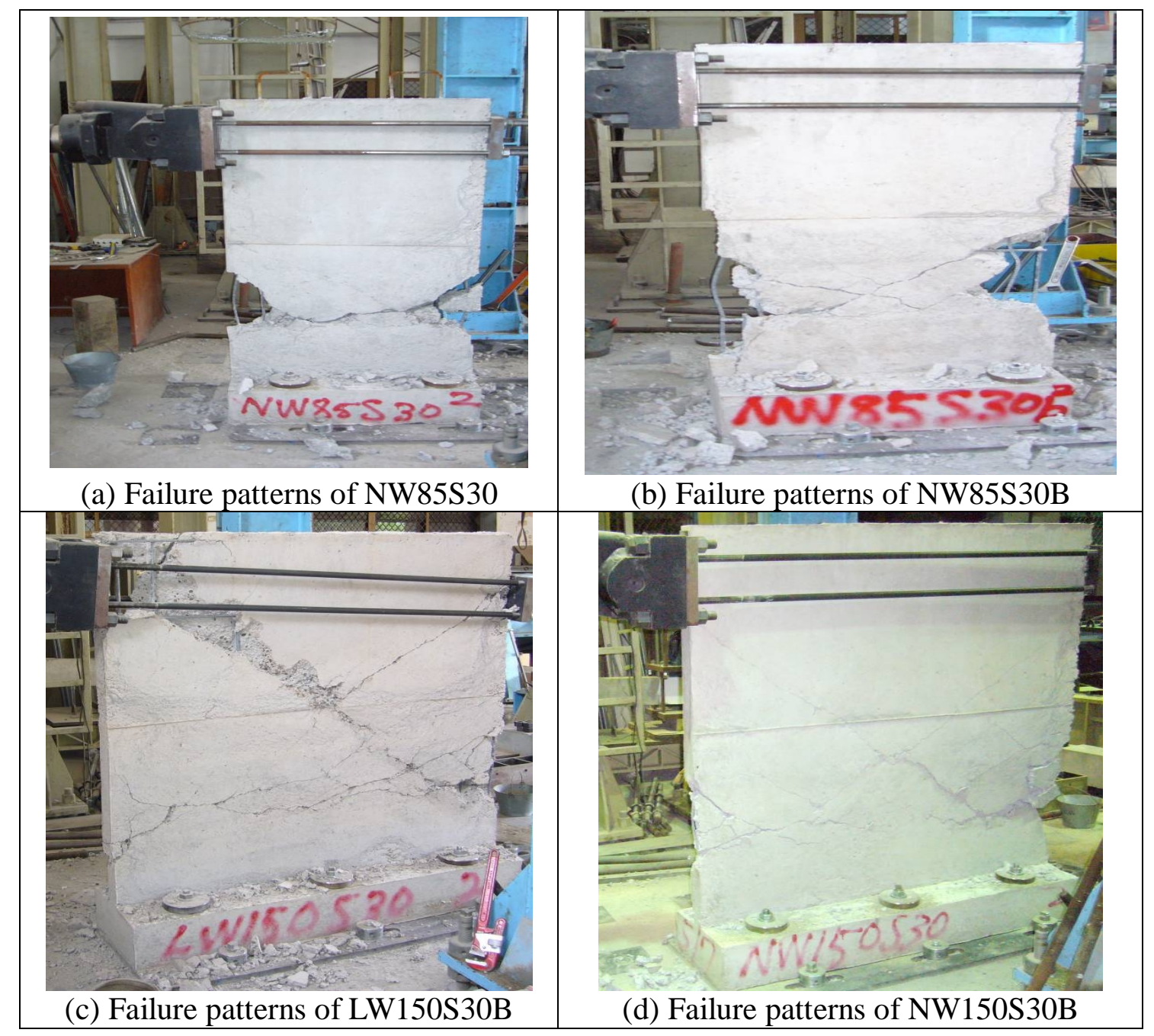

Figure 3. Failure patterns of RLAC and RNAC wall specimens

The failure pattern of specimens are demonstrated in Figure 2(c) and Figure 3(b). The reason behind this is that after fire-resistance test, the concrete will gradually exhibit the phenomenon of decomposition of cement hydrates and pellets decay, leading to the decrease in structural strength of wall specimens and affecting the failure patterns of specimens. Failure patterns of walls with different widths are shown in Figure 2(c) and Figure 3(c). LW85S30B specimens with the width of $85 \mathrm{~cm}$ generated diagonal and horizontal cracks simultaneously in the beginning and these cracks were getting wider and deeper following the repeated lateral loads; while the cracks on LW150S30B specimens were initially diagonal, which then extended to the center and became horizontal cracks. Under the repeated lateral loads, those cracks were also widened and deepened. The above results showed that comparing to the $150 \mathrm{~cm}$ wide walls, the $85 \mathrm{~cm}$ wide walls had more flexure effects and a flexural failure pattern; while the $150 \mathrm{~cm}$ wide walls had more shear effects and with the shear failure pattern.

NW85S30B specimens with the width of $85 \mathrm{~cm}$ initially generated diagonal and horizontal cracks on both sides of the wall simultaneously. These cracks got wider and deeper following the repeated lateral loads. NW150S30B wall specimens with the width of $150 \mathrm{~cm}$ generated diagonal cracks on both sides of the wall initially and these cracks were getting wider and deeper following the back and forth pressures of loads, as shown in Figure 3(b) and (d). The test results showed that RLAC and RNAC walls exerted the same influence on failure patterns. 


\section{Conclusions}

The study found that there was no significant difference on the failure pattern,between RLAC and RNAC walls after the fire-resistance test under the effects of repeated loads. The failure pattern of RLAC walls with the width of $30 \mathrm{~cm}$ after the test of fire-resistance and under the effects of repeated loads is bending moment of flexure, while under the same conditions, the failure pattern of RLAC walls with smaller steel spacing is a combination of flexure and shear forces.

\section{References}

[1] Gales J, Bisby LA. Gillie M. Unbonded post tensioned concrete in fire: A review of data from furnace tests and real fires. Fire Saf J 2011; 46: 151-163.

[2] Demirdag S, Gunduz L. Strength properties of volcanic slag aggregate lightweight concrete for high performance masonry units. Constr Build Mater 2008; 22: 135-142.

[3] Jen-Hao Chi, Jun-Ren Tang, Cheer-Germ Go, Yue-Lin Huang. Research on Seismic Resistance and Mechanic Behavior of Reinforced Lightweight Aggregate Concrete Walls after high temperature. Fire Mater 2014; 38, 789-805. 